\title{
ESTIMATING CAPITAL AND OPERATIONAL COSTS OF BACKHOE SHOVELS
}

\author{
Ahmad Reza Sayadi ${ }^{1}$, Ali Lashgari ${ }^{2}$, Mohammad Majid Fouladgar ${ }^{3}$, Miroslaw J. Skibniewski ${ }^{4}$ \\ ${ }^{1,2}$ Department of Mining Engineering, Tarbiat Modares University, Tehran, Iran \\ ${ }^{3}$ Graduated from Tarbiat Modares University, Fateh Research Group, Tehran, Iran \\ ${ }^{4}$ Department of Management, Bialystok University of Technology, 16-001 Kleosin, Poland \\ E-mails: ${ }^{1}$ sayadi@modares.ac.ir (corresponding author); ${ }^{2}$ ali.lashgari@gmail.com; \\ ${ }^{3}$ manager@fatehidea.com; ${ }^{4}$ mirek@umd.edu \\ Received 18 Jun. 2011; accepted 21 Sept. 2011
}

\begin{abstract}
Material loading is one of the most critical operations in earthmoving projects. A number of different equipment is available for loading operations. Project managers should consider different technical and economic issues at the feasibility study stage and try to select the optimum type and size of equipment fleet, regarding the production needs and project specifications. The backhoe shovel is very popular for digging, loading and flattening tasks. Adequate cost estimation is one of the most critical tasks in feasibility studies of equipment fleet selection. This paper presents two different cost models for the preliminary and detailed feasibility study stages. These models estimate the capital and operating cost of backhoe shovels using uni-variable exponential regression (UVER) as well as multi-variable linear regression (MVLR), based on principal component analysis. The UVER cost model is suitable for quick cost estimation at the early stages of project evaluation, while the MVLR cost function, which is more detailed, can be useful for the feasibility study stage. Independent variables of MVLR include bucket size, digging depth, dump height, weight and power. Model evaluations show that these functions could be a credible tool for cost estimations in prefeasibility and feasibility studies of mining and construction projects.
\end{abstract}

Keywords: loading equipment, backhoe shovel, cost estimation, multi-variable linear regression, principal component analysis, mining and construction.

\section{Introduction}

Earthmoving operations are an important part of construction and mining projects, and mainly include excavation, loading, site preparation, embankment construction, compacting, backfilling, surfacing and hauling. These operations are equipment-intensive, characterized by the development of large fleets (Hassanien, Moselhi 2002). Earthmoving is therefore often one of the most important operations in many mining and construction projects in terms of its effect on costs and productivity (Gransberg et al. 2006; Tatari, Skibniewski 2006; Park et al. 2010).

The owning and operation of these equipment fleets represent a considerable part of the early costs for large contractors involved in heavy construction engineering and mining projects (Skibniewski, Armijos 1990; Fan et al. 2008). Moreover, machine owners seek to minimize the cost of operation by optimum selection of the equipment (Zavadskas, Vilutienè 2006). Consequently, it is a main concern of equipment managers to limit and reduce the overall cost of this task. Their responsibilities include selecting and optimizing the equipment fleet, as well as reducing the cost and optimizing productivity.

In equipment planning for an earthmoving operation, a decision should be made on what machines to employ in the operation. Most assessment utilise an average operting cost over the life of the equipment (Noakes,
Lanz 1993). In making such a decision, many interactions between engineering and economic considerations must be taken into account. The process of selecting appropriate machines, however, can generally follow a decisionmaking path with the individual steps of selection of the type and model of the machine, determination of the number of machines and choice of the most appropriate machine.

The decision-maker should consider all the alternatives, as well as the project specification and economic issues, in order to choose the most appropriate loading equipment fleet. This decision has a significant impact on the results of the feasibility study. Therefore, managers need to have an accurate and simple cost estimation tool to select the most suitable equipment fleet, which will meet production targets and minimize overall cost (Twort, Rees 2004).

The selection and evaluation of material handling equipment is a complex procedure that requires working knowledge and experience of the techniques of cost estimation as well as knowledge of equipment management, because the work of providing cost evaluations needs the manager to be familiar with equipment management to present precise cost estimations.

In the first stages of mining and construction project evaluation, no adequate estimation of expenses is possible, because access to an expert who is knowledgeable in 
both equipment management and cost estimation is not simple, adequate data is not available, and many different alternatives need to be considered. Moreover, this evaluation is time consuming and costly. Accordingly, an accurate and rapid estimation tool is beneficial for equipment managers.

A variety of equipment can be used in material handling operations. Based on its operational function, earthmoving equipment can be classified as loading (excavating) and hauling machines and some types of machines can function as both (Nichols, Day 1999). Cable shovels, hydraulic shovels, wheel loaders and backhoe shovels are the most common equipment used in loading operations.

The level of detail required in any assessment can be dependent on many factors, such as management guidelines, data source and evaluation time and budget (Noakes, Lanz 1993). It is important that the desired or necessary level of details as well as data source are clarified, prior to proceeding with cost estimation.

Backhoe shovels are very popular for digging, loading and flattening operations. In this paper, two different cost models for backhoe shovels are presented, based on uni-variable exponential (UVER) and multi-variable linear regression (MVLR). The UVER cost model is useful for quick cost estimation at the early stages of a project. This model is particularly suited for making quick cost estimates where only one specific design parameter is available. While the MVLR, based on principal component analysis (PCA), is suitable for detailed estimates at the feasibility study stage.

In order to demonstrate the capabilities of proposed cost estimation models, a case example of a real world project was performed using a particular project's conditions. The estimated costs are compared with those of the actual project records.

\section{Literature review}

A number of models have been established in attempts to shortcut the construction and mining cost estimating process (Table 1). These relate the cost to certain factors in a process or a unit. In these models, machine capacity usually has been used as independent variables in univariate functions (Mular, Poulin 1998; Camm 1994; O'Hara, Suboleski 1992). For instance, the cost of an excavator may be related to its bucket capacity. The relationship may be expressed in a formula or a graph. Some of these models are old, and therefore subject to modern review. Moreover, as the capital or operating cost models are univariable, the roles of the other effective parameters have simply been disregarded. Multivariate cost estimation models, on the basis of up-to-date data, will overcome these shortcomings.

Table 1. The various applications of construction and mining cost estimation

\begin{tabular}{|c|c|c|}
\hline Proposed by & Year & Application \\
\hline Hwang & 2011 & Prediction of cost indexes for construction projects using time series \\
\hline Asmar et al. & 2011 & $\begin{array}{l}\text { Estimation of highway project costs using project evaluation and review tech- } \\
\text { nology }\end{array}$ \\
\hline Thal et al. & 2010 & $\begin{array}{l}\text { Prediction of the required cost contingency for air force construction projects, } \\
\text { using multiple linear regression }\end{array}$ \\
\hline Sayadi et al. & $2010 \mathrm{a}$ & $\begin{array}{l}\text { Estimating maintenance cost of loading and hauling equipment using multiple } \\
\text { linear regression }\end{array}$ \\
\hline Sayadi et al. & $2010 \mathrm{~b}$ & Estimation of hoisting equipment cost for underground mines \\
\hline Sonmez and Ontepeli & 2009 & Cost estimation of urban railway projects \\
\hline R.S. Means Company & 2005 & Presenting cost data for all phases of building construction \\
\hline Wilmot and Mei & 2005 & Estimation of highway construction costs indexes using neural network \\
\hline Pratt & 2004 & Pricing construction equipment \\
\hline Mular & 1982 & Estimation of capital costs of mining and mineral processing equipment using \\
\hline Mular and Poulin & 1998 & UVER method \\
\hline Camm & 1991,1994 & Development of UVER cost functions for surface and underground mining \\
\hline Noakes and Lanz & 1993 & $\begin{array}{l}\text { Estimating the costs of mining and milling industry, using graphical or for- } \\
\text { mulation methods }\end{array}$ \\
\hline O'Hara and Suboleski & 1992 & $\begin{array}{l}\text { Development of cost formulas as estimators of capital and operating costs of } \\
\text { mining and milling }\end{array}$ \\
\hline Petrich and Dewey & 1987 & A computer model which utilizes O’Hara's cost estimation model \\
\hline Stebbins & 1987 & $\begin{array}{l}\text { Using univariate exponential regression method for small placer mines cost } \\
\text { prediction }\end{array}$ \\
\hline USBM & 1987 & Estimation of mining and milling cost items, using regression analysis \\
\hline Collier & 1987 & Fundamentals of building and construction estimating and cost accounting \\
\hline Mular & 1982 & Estimation of mining and milling costs using regression analysis \\
\hline O’Hara & $\begin{array}{l}1980 \\
1981\end{array}$ & Surface and underground mining cost estimation using exponential regression \\
\hline Infomine $^{1}$ & Annually & Cost estimation guide for mine and mile equipment \\
\hline
\end{tabular}

\footnotetext{
${ }^{1}$ Cost.infomine.com
} 


\section{Data and method}

\subsection{Data}

32 different sizes of backhoe shovels, working in construction and mining projects in the United States are considered and their economic data as well as machine specifications are considered (InfoMine 2007, 2010). The economic data are classified into two types, as capital (CC) and operating costs (OC). The $\mathrm{CC}$ is based on the US dollar (2010) while the OC is based on US dollars per hour. The operating costs items include overhaul (parts and labor), maintenance (parts and labor), power, lubrication and wear on parts (the cost of the operator's time is not included here) and the technical parameters are bucket size (BS), digging depth (DD), dumping height (DH), weight (W) and power (HP) (Noakes, Lanz 1993). The average and standard deviation of all the parameters and data ranges are given in Table 2.

Table 2. Description of data

\begin{tabular}{lccccc}
\hline \multicolumn{1}{c}{ Parameter } & & Min & Max & Mean & St. dev. \\
\hline Capital cost (CC) & M\$ & 0.113 & 16.2 & 3.69 & 3.67 \\
Operating cost (OC) & $\$ / \mathrm{h}$ & 12.14 & 656 & 220.23 & 191.04 \\
Bucket size (BS) & $\mathrm{cu} \mathrm{m}$ & 0.28 & 39.8 & 12.61 & 11.45 \\
Digging depth (DD) & $\mathrm{m}$ & 4.1 & 16.2 & 9.248 & 2.68 \\
Dump height (DH) & $\mathrm{m}$ & 5.1 & 15.9 & 10.22143 & 3.16685 \\
Machine weight (W) & ton & 8.03 & 811 & 240.5 & 210.6 \\
Power (HP) & $\mathrm{hp}$ & 54 & 3800 & 1109.8 & 983.16 \\
\hline
\end{tabular}

The statistical analysis is applied and the results confirm the normal distribution of different variables, but a significant correlation is observed between independent variables (Eq. (1)):

$$
\begin{aligned}
& \text { BS DD DH W HP } \\
& \begin{array}{l}
\text { BS } \\
\text { DD } \\
\text { DH } \\
\text { W }
\end{array}\left[\begin{array}{lllll}
1.000 & 0.865 & 0.921 & 0.976 & 0.949 \\
0.965 & 1.000 & 0.901 & 0.868 & 0.850 \\
0.97 & 0.901 & 1.000 & 0.886 & 0.856 \\
0.946 & 0.868 & 0.886 & 1.000 & 0.939 \\
0.949 & 0.850 & 0.856 & 0.939 & 1.000
\end{array}\right] .
\end{aligned}
$$

One of the key assumptions of linear regression analysis is that there is no multi-collinearity (mutual correlation) among the independent variables of the regression model (Sharma 1996). In multiple regression, one of the major diffculties with the usual least squares estimators is the problem of multi-collinearity, which occurs when there are near-constant linear functions of two or more of the predictor, or regressor, variables (Gunst 1983). When highly correlated explanatory parameters are used in a MVLR model, multi-collinearity causes unstable prediction of regression coefficients, numerical inaccuracies in calculating the estimates of regression coefficients, inaccurate rejection of parameters and statistical imprecision (Jennrich 1995). Consequently, the present correlation should be considered and eliminated before applying the MVLR (Gujarati 2003).

\subsection{Research framework}

This paper presents two different cost models for backhoe shovels. Figure 1 shows a normal material loading operation using a backhoe shovel and dump truck.

These models help the cost estimators to make a quick and up-to-date estimation of capital and operating costs with an acceptable level of accuracy for the different stages of the feasibility study. The first model estimates the costs based on the bucket size of the backhoes, using the UVER technique.

The second model is useful for in-depth estimations, and estimates the costs as functions of different specification parameters of backhoe shovels, including the bucket size (BS), digging depth (DD), dump height (DH), power (HP) and weight (W) of the machine. This model is presented using MVLR, based on PCA.

The PCA technique can be used to eliminate the correlation between independent variables. This is attained by transforming the original variables into a new set of variables, called the Principal Components (PCs). A PC is a weighted linear combination of all the original variables, which is uncorrelated with the other PCs. PCs are ordered so that the first few preserve most of the variation in all of the initial parameters. The direction of highest variance of the independent variables is represented by the first PC (PC1). The direction of the second highest variance (PC2) would be orthogonal to PC1 and the contribution of the PCs to the overall variation decreases from step to step. PCs are orthogonal by definition, so any pair of PCs will have zero correlation. The variance of the data in the corresponding PCs is represented by the eigenvalues, and the eigenvector of each $\mathrm{PC}$ is equal to the loading on it (Jolliffe 1986). PCs are used in conjunction with a variety of other statistical techniques. One area in which this activity has been extensive is regression analysis. In this hybrid method, the values obtained by PCA are used as inputs in the MVLR.

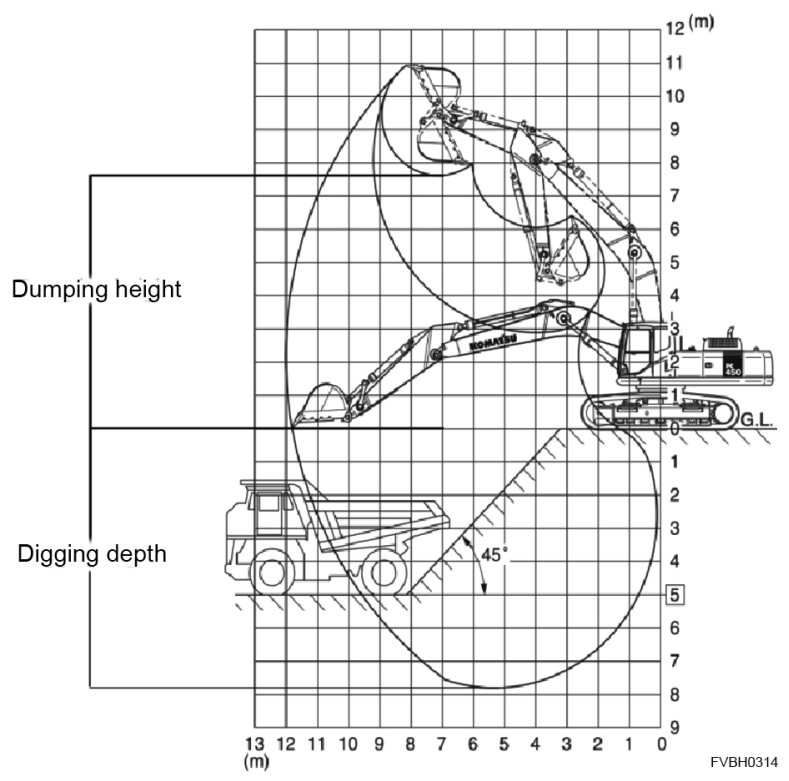

Fig. 1. A normal material loading operation by using backhoe shovel and dump track (www.komatsu.com) 
The selection of a subset of PCs to use as independent variables of MVLR depends on the nature of the data. The main objective in many applications of PCA is to replace the elements of original variables by a much smaller number of PCs, which nevertheless discard only a small amount of the variation of the original variables and useful information. In these cases the number of PCs selected to use as independent variables in the MVLR is an important issue. But, in the cases in which the major objective of using the PCA technique is to solve the problem of multi-collinearity, all PCs can be contributed to the MVLR model (Jolliffe 1986). Concerning the present study, all scores obtained from the PCA technique are used as regressor variables in the MVLR model. Performing the MVLR, the relationship between costs (as dependent variables) and PCs (as independent variables) are established.

In order to estimate the cost as a function of the original variables, the eigenvectors of the correlation matrix are multiplied in MVLR coefficients (B coefficients). Since, when applying the PCA technique, all the variables are standardized, it is necessary to transform them to their initial positions with actual means and standard deviations as follow:

$$
x^{*}=(x-m) / s d,
$$

where: $x^{*}$ is the standardized value of the original variable $(x)$ and $m$ and $s d$ represent the mean and standard deviation of $x$.

To assess the performance of the models, the Mean Absolute Error Rates (MAER) of different functions are calculated as follows (Kim et al. 2004):

$$
M A E R=\left[\sum\left|\left(C_{e}-C_{a}\right) / C_{a}\right| \cdot 100\right] / n,
$$

where: $\mathrm{Ce}$ is the estimated backhoe shovel cost, $\mathrm{Ca}$ is the actual backhoe shovel cost, and $\mathrm{n}$ is the number of data.

\section{Results}

\subsection{Univariate exponential regression}

Applying the UVER, two different sets of functions are developed for estimation of the capital and operating costs of backhoe shovels as functions of different machine specific parameters. The UVER functions are in the form of $Y=a \times$ (parameter $^{m}$, where $\mathrm{Y}$ is the estimated cost. Whereas $a$ and $m$ are constants determined by the regression analysis. Eqs (4) and (5) show UVER functions to calculate capital and operating costs as functions of bucket size of backhoe shovels and the relationships are expressed as graphs in Figs 2 and 3.

$$
\begin{gathered}
C C(\$)=34076 \times B S^{0.932}, R^{2}=95.0 \% ; \\
O C(\$ / h)=32.91 \times B S^{0.765}, R^{2}=93.7 \% .
\end{gathered}
$$

The following equations show UVER functions based on the other backhoe shovel specification parameters:

$$
C C(\$)=164.3 \times D D^{4.256}, R^{2}=68.6 \% ;
$$

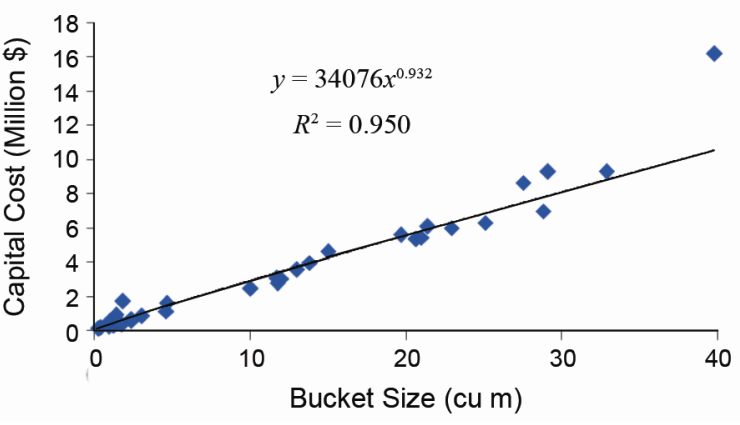

Fig. 2. UVER result for capital cost

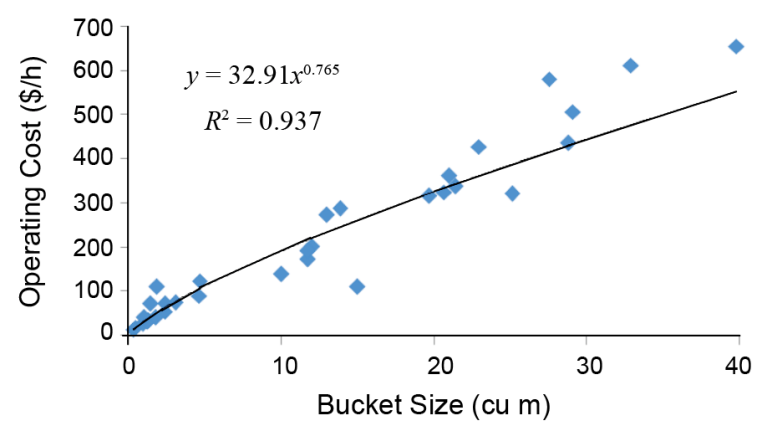

Fig. 3. UVER result for operational cost

$$
\begin{aligned}
& C C(\$)=435.8 \times D H^{3.698}, R^{2}=85.1 \% ; \\
& C C(\$)=4.279 \times W^{1.096}, \quad R^{2}=97.1 \% ; \\
& C C(\$)=878.2 \times H P^{1.176}, \quad R^{2}=93.9 \% ; \\
& O C(\$ / h)=0.091 \times D D^{3.340}, \mathrm{R}^{2}=74.8 \% ; \\
& O C(\$ / h)=0.079 \times D H^{3.268}, \mathrm{R}^{2}=85.4 \% ; \\
& O C(\$ / h)=0.003 \times W^{0.893}, \mathrm{R}^{2}=94.5 \% ; \\
& O C(\$ / h)=0.238 \times H P^{0.971}, \quad \mathrm{R}^{2}=93.7 \% .
\end{aligned}
$$

\subsection{Multiple regression analysis}

Performing the PCA technique on these five backhoe shovel parameters to describe their interrelation pattern, the number of PCs will usually be equal to the number of independent original variables. Table 3 shows the eigenvectors of the correlation matrix that represent the matrix of the weights for the PCs, which demonstrates the relative importance of each standardized parameter in the PC calculations (He, Ma 2010).

Table 3. Eigenvector of correlation matrix

\begin{tabular}{lccccc}
\hline & BS & DD & DH & W & HP \\
\hline $\mathrm{PC}_{1}$ & -0.4577 & -0.2837 & 0.2550 & -0.1631 & 0.7864 \\
$\mathrm{PC}_{2}$ & -0.4348 & 0.6541 & -0.5865 & -0.1340 & 0.1452 \\
$\mathrm{PC}_{3}$ & -0.4430 & 0.4333 & 0.6805 & 0.2903 & -0.2620 \\
$\mathrm{PC}_{4}$ & -0.4538 & -0.3275 & -0.0078 & -0.6497 & -0.5145 \\
$\mathrm{PC}_{5}$ & -0.4463 & -0.4434 & -0.3576 & 0.6701 & -0.1648 \\
\hline
\end{tabular}


The eigenvalue of the correlation matrix is shown in Table 4. There are no multi-collinearities between PCs, because they are uncorrelated, and the regression calculations are also simplified. If all the PCs are submitted to the MVLR, then the outcome is equal to the model attained by least squares, so the significant variances caused by multi-collinearities have not departed. However, estimation of the least squares predictions via MVLR based on PCA may be more stable than common calculation (Flury, Riedwyl 1988). Therefore, in this study all five PCs ware selected as inputs to the MVLR model.

Table 4. Eigenvalue of correlation matrix

\begin{tabular}{lcccc}
\hline & Eigenvalue & $\begin{array}{c}\text { Total } \\
\text { Variance \% }\end{array}$ & $\begin{array}{c}\text { Cumulative } \\
\text { Eigenvalue }\end{array}$ & Cumulative \% \\
\hline $\mathrm{PC}_{1}$ & 4.61 & 92.14 & 4.61 & 92.14 \\
$\mathrm{PC}_{2}$ & 0.21 & 4.22 & 4.82 & 96.36 \\
$\mathrm{PC}_{3}$ & 0.11 & 2.16 & 4.93 & 98.52 \\
$\mathrm{PC}_{4}$ & 0.06 & 1.18 & 4.99 & 99.70 \\
$\mathrm{PC}_{5}$ & 0.01 & 0.30 & 5.00 & 100.00 \\
\hline
\end{tabular}

To identify non-significant PCs and derive the best estimation functions for the costs of a backhoe shovel, MVLR is performed on the PC scores using stepwise variable selection procedures (Sousa et al. 2007). Tables 5 and 6 summarize the results of the MVLR model on the capital and operating costs of these equipments, respectively. The regression coefficients of $\mathrm{PCs}$ are highlighted in the "B" Column. The "Beta" coefficients are the standardized regression coefficients. It is important to note that the advantage of "Beta" coefficients in comparison with "B" coefficients is that their magnitudes facilate the assessment of the relative contribution of each PC in the estimation function. As indicated in Tables 5 and $6, \mathrm{PC}_{1}$ is the most effective variable in the cost functions (with regard to "Beta" coefficient). A t-Test is used to assess the significance of the regression coefficients. The significant variables are given in bold in Tabes 5 and 6. Eqs (14) and (15) show the relationships between costs and PCs:

$$
\begin{aligned}
C C(\$)= & -1648260 \times P C_{1}-1516023 \times P C_{2}- \\
& 973745 \times P C_{3}+3690728 ;
\end{aligned}
$$

$$
O C(\$ / h)=-86.305 \times P C_{1}-62.27 \times P C_{2}+220.229 \text {. (15) }
$$

Table 7 summarizes the coefficients of determination for the models. As can be observed in the "R-square" (the coefficient of determination) column in Table 7, about $96.37 \%$ of variation in the operating cost of backhoe shovels is explained by the proposed MVLR model. R-square has a weakness; each additional variable used in the equation will, at least, result in a higher RSquare, even when the new variable causes the equation to become less efficient. The adjusted R-Square $\left(\operatorname{adj~} \mathrm{R}^{2}\right.$ ) value is an attempt to correct this shortcoming by adjusting both the numerator and the denominator of $\mathrm{R}$-square by their respective degrees of freedom (Gujarati 2003). It is adjusted by dividing the error sum and total sums of squares through their respective degrees of freedom (Eq. (16)) (Gujarati 2003):

$$
\operatorname{adj} R^{2}=1-[(\operatorname{Res} S S / d f) /(\text { Total } S S / d f)] \text {, }
$$

where Res SS is the error sums of squares, the Total SS is the total sums of squares and $d f$ is their respective degree of freedom.

The eigenvectors of the correlation matrix (Table 3) are multiplied by the "B" coefficient calculated using MVLR (Tables 5 and 6) to obtain the costs as functions of the original variables. Then the new standardized coefficients are transformed to their initial position, by Eq. (2). The final MVLR cost estimation functions are presented as follows:

$$
\begin{aligned}
C C= & 81770 B S+110325 D D-186064 D H+ \\
& 5.946 W+1786.3 H P+129073 ; \\
O C= & 4.99 B S-1.193 D D+3.554 D H+ \\
& 0.00028 W+0.067 H P-10.69 .
\end{aligned}
$$

Table 5. Regression summary for capital cost (\$) for backhoe shovel

\begin{tabular}{ccccccc}
\hline & Beta & Std. Error of Beta & B & Std. Error of B & $T(26)$ & P-value \\
\hline Intercept & & & $\mathbf{3 6 9 0 7 2 8}$ & $\mathbf{1 1 1 1 4 7 . 1}$ & $\mathbf{3 3 . 2 0 5 8}$ & $\mathbf{0 . 0 0 0 0 0 0}$ \\
PC1 & $\mathbf{- 0 . 9 6 4 4 3 0}$ & $\mathbf{0 . 0 3 0 7 8 4}$ & $\mathbf{- 1 6 4 8 2 6 0}$ & $\mathbf{5 2 6 1 1 . 3}$ & $\mathbf{- 3 1 . 3 2 9 0}$ & $\mathbf{0 . 0 0 0 0 0 0}$ \\
PC2 & $\mathbf{- 0 . 1 8 9 7 9 7}$ & $\mathbf{0 . 0 3 0 7 8 4}$ & $\mathbf{- 1 5 1 6 0 2 3}$ & $\mathbf{2 4 5 8 9 0 . 3}$ & $\mathbf{- 6 . 1 6 5 4}$ & $\mathbf{0 . 0 0 0 0 0 2}$ \\
PC3 & $\mathbf{- 0 . 0 8 7 3 2 4}$ & $\mathbf{0 . 0 3 0 7 8 4}$ & $\mathbf{- 9 7 3 7 4 5}$ & $\mathbf{3 4 3 2 6 9 . 2}$ & $\mathbf{- 2 . 8 3 6 7}$ & $\mathbf{0 . 0 0 8 7 1 6}$ \\
PC4 & -0.038305 & 0.030784 & -578859 & 465197.5 & -1.2443 & 0.224479 \\
PC5 & -0.010976 & 0.030784 & -330291 & 926394.0 & -0.3565 & 0.724318 \\
\hline
\end{tabular}

Table 6. Regression summary for operating cost $(\$ / \mathrm{h})$ for backhoe shovel

\begin{tabular}{ccccccc}
\hline & Beta & Std. Error of Beta & B & Std. Error of B & $T(26)$ & P-value \\
\hline Intercept & & & $\mathbf{2 2 0 . 2 2 9}$ & $\mathbf{7 . 0 2 9}$ & $\mathbf{3 1 . 3 3 1}$ & $\mathbf{0 . 0 0 0}$ \\
PC1 & $\mathbf{- 0 . 9 7 0}$ & $\mathbf{0 . 0 3 7}$ & $\mathbf{- 8 6 . 3 0 5}$ & $\mathbf{3 . 3 2 7}$ & $\mathbf{- 2 5 . 9 3 9}$ & $\mathbf{0 . 0 0 0}$ \\
PC2 & $\mathbf{- 0 . 1 5 0}$ & $\mathbf{0 . 0 3 7}$ & $\mathbf{- 6 2 . 2 7 2}$ & $\mathbf{1 5 . 5 5 1}$ & $\mathbf{- 4 . 0 0 4}$ & $\mathbf{0 . 0 0 0}$ \\
PC3 & -0.015 & 0.037 & -8.592 & 21.709 & -0.396 & 0.695 \\
PC4 & 0.014 & 0.037 & 11.025 & 29.420 & 0.375 & 0.711 \\
PC5 & -0.024 & 0.037 & -37.833 & 58.587 & -0.646 & 0.524 \\
\hline
\end{tabular}


Table 7. MVLR coefficients of determination

\begin{tabular}{lcc}
\hline & R-square & Adjusted R-square \\
\hline Capital Cost & 0.754 & 0.9706 \\
Operating Cost & 0.9637 & 0.9567 \\
\hline
\end{tabular}

The estimated costs can be updated as follows:

$$
C_{x}=\left(I_{x} \times C_{2010}\right) / I_{2010},
$$

where $C$ indicates cost and $x$ and $I$ are proposed year and cost index, respectively.

\subsection{Model performance}

In this study, each model's performance is measured with the MAER, which was determined with Eq. (3). The MAER obtained from the UVER and MVLR models for cost estimation functions are presented in Table 8 . As is observed, the MAER values are smaller for the multiple regression analyses for both the capital and the operating costs, therefore, by using MVLR functions the capital and operating costs can be estimated with a error no more that $13.85 \%$ and $11.44 \%$ in cases of capital and operating costs, respectively, while these bounds for UVER functions is about 19.49 and 20.89 for capital and operating costs, respectively.

Table 8. The MAER obtained from the UVER and MVLR

\begin{tabular}{lcc}
\hline & UVER & MVLR \\
\hline Capital Cost & 19.49 & 13.85 \\
Operating Cost & 20.89 & 11.44 \\
\hline
\end{tabular}

\section{Case example}

Sungun Copper Mine is located in East Azerbijan province approximately $125 \mathrm{Km}$ east of the city of Tabriz is one of the main copper deposits of Iran. Feasibility studies were shown that open pit mining technique is the most appropriate method for Sungun Copper Mine (Bazzazi et al. 2009). By using open-pit method, the waste to ore ratio in this mine will be $1.8: 1$ and an amount of 384 million tons of ore with 0.665 percentage of copper grade can be mined. Total Sungun Copper Mine's life is evaluated to be 31 years with an annual production of 7 million tons in the first 5 years and 14 million tons for the remaining 26 years (Karan Darya Co. 2011). Fig. 4 shows the location map of Sungun Copper complex.

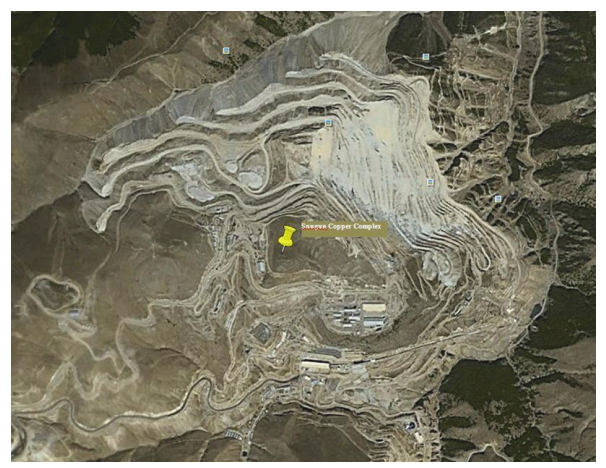

Fig. 4. Location map of Sungun Copper Complex
The site preparation project for Sungun Copper Complex, including over burden removal, access-road construction and smelter complex site preparation began in the fourth quarter of 2010. The site plan of the project has been shown in Fig. 5 .

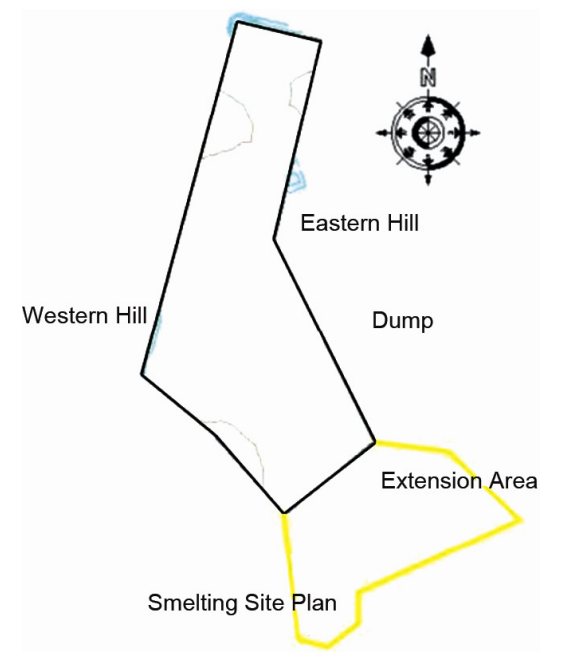

Fig 5. Site plan of Sungun Copper Complex (Karan Darya Co. 2011)

This project needs about 1.3 million $\mathrm{m}^{3}$ of excavation and overburden removal operation including soil and rocky soil removal operations. The equipment fleet used in this project is listed in Table 9.

Table 9. Equipment fleet used in the project

\begin{tabular}{l|c}
\hline \multicolumn{1}{c|}{ Equipment } & Number \\
\hline Backhoe shovel & 20 \\
\hline Wheel loader & 14 \\
\hline Dozer & 17 \\
\hline Truck & 62 \\
\hline Grader & 4 \\
\hline Compactor & 4 \\
\hline Tractor & 1 \\
\hline Truck, water & 2 \\
\hline
\end{tabular}

Table 10 lists the model, number and specification of backhoe shovels used in this project.

Table 10. Backhoe shovels used in the project

\begin{tabular}{l|c|c|c|c|c|c}
\hline \multicolumn{1}{c|}{ Model } & Number & $\begin{array}{c}\text { BS } \\
(\mathrm{cu} \mathrm{m})\end{array}$ & $\begin{array}{c}\text { DD } \\
(\mathrm{m})\end{array}$ & $\begin{array}{c}\text { DH } \\
(\mathrm{m})\end{array}$ & $\begin{array}{c}\mathrm{W} \\
(\text { ton })\end{array}$ & HP \\
\hline $\begin{array}{l}\text { Komatsu } \\
\text { PC220 }\end{array}$ & 5 & 1.28 & 6.7 & 7.035 & 22.84 & 168 \\
\hline $\begin{array}{l}\text { Komatsu } \\
\text { PC200 }\end{array}$ & 4 & 1.17 & 6.89 & 6.095 & 20.63 & 155 \\
\hline $\begin{array}{l}\text { Hyundai } \\
\text { 250LC }\end{array}$ & 2 & 1.07 & 6.05 & 6.86 & 25.49 & 163 \\
$\begin{array}{l}\text { Hyundai } \\
\text { 320LC }\end{array}$ & 2 & 1.14 & 6.37 & 7.05 & 32 & 237 \\
\hline $\begin{array}{l}\text { New Holland } \\
\text { E265 BJ }\end{array}$ & 1 & 1.1 & 7.01 & 7.7 & 28.27 & 184 \\
\hline $\begin{array}{l}\text { New Holland } \\
\text { E215 BJ-ST }\end{array}$ & 3 & 1.223 & 6.7 & 9.47 & 21.7 & 150 \\
\hline $\begin{array}{l}\text { Daewoo } \\
\text { Doosan 230 }\end{array}$ & 3 & 0.92 & 6.61 & 6.985 & 21.5 & 163 \\
\hline
\end{tabular}


MVLR model has been used to estimate operational cost of backhoe shovels. Table 11 shows the estimated cost of each machine by using proposed MVLR model vs. the actual operational costs calculated from in site operations as well as the calculated MAER values.

Table 11. Estimated vs. actual operational costs

\begin{tabular}{l|c|c|c}
\hline \multicolumn{1}{c|}{ Model } & $\begin{array}{c}\text { Estimated } \\
\text { operational } \\
\text { cost }(\$ / \mathrm{h})\end{array}$ & $\begin{array}{c}\text { Estimated } \\
\text { operational } \\
\text { cost }(\$ / \mathrm{h})\end{array}$ & MAER (\%) \\
\hline $\begin{array}{l}\text { Komatsu } \\
\text { PC220 }\end{array}$ & 24.02 & 27.18 & 11.63 \\
\hline $\begin{array}{l}\text { Komatsu } \\
\text { PC200 }\end{array}$ & 19.03 & 22.24 & 14.43 \\
\hline $\begin{array}{l}\text { Hyundai } \\
\text { R250 LC }\end{array}$ & 22.79 & 24.52 & 7.05 \\
\hline $\begin{array}{l}\text { Hyundai } \\
\text { R320 LC }\end{array}$ & 28.41 & 27.32 & 3.99 \\
\hline $\begin{array}{l}\text { New Holland } \\
\text { E265 BJ }\end{array}$ & 26.19 & 28.93 & 9.47 \\
\hline $\begin{array}{l}\text { New Holland } \\
\text { E215 BJ-ST }\end{array}$ & 31.18 & 29.75 & 4.81 \\
\hline $\begin{array}{l}\text { Daewoo } \\
\text { Doosan 230 }\end{array}$ & 21.81 & 25.54 & 14.60 \\
\cline { 2 - 4 } & \multicolumn{2}{|c}{ Average MAER: } & $9.43 \%$ \\
\cline { 2 - 4 }
\end{tabular}

Regarding to the number of backhoe shovels used in the project, the total operational cost of backhoe shovel fleet is estimated about 483.78 US\$/hour, while the actual in site operational cost of these equipment is recorded as 523.34 US\$/hour.

\section{Conclusions}

The objective of this paper was to establish reliable cost estimating models for backhoe shovels which are popular for material handling in mining and construction projects. For this, regression techniques have been adopted due to the mathematical background and their explanatory values. Based on the collected data, two cost estimation models in the form of uni-variable exponential regression (UVER) and multi-variable linear regression (MVLR) have been developed. These models are quick, easy and accurate tools and can be useful for making accurate decisions about the size of the loading equipment fleet in construction and mining projects. The UVER model presents a rough estimate suitable for preliminary cost estimations while the MVLR model is more detailed with reasonable accuracy and can be appropriate for detailed estimates in feasibility studies.

\section{Acknowledgements}

We would like to acknowledge the support and hard work of M. Eng. Hassanzadeh as well as the other managers of Sungun Copper Complex who were instrumental in the successful delivery of the case example referred to in this work. In addition we would like to note that the reviewers made very useful and objective comments that helped improve the final manuscript; their input is very much appreciated.

\section{References}

Asmar, M. El.; Hanna, A. S.; Whited, G. 2011. New approach to developing conceptual cost estimates for highway projects, Journal of Construction Engineering and Management ASCE 137(11): 942-949.

http://dx.doi.org/10.1061/(ASCE)CO.1943-7862.0000355

Bazzazi, A. A.; Osanloo, M.; Karimi, B. 2009. Optimal open pit mining equipment selection using fuzzy multiple attribute decision making approach, Archive of Mining Science 54(2): 301-320.

Camm, T. W. 1991. Simplified cost models for prefeasibility mineral evaluations. USBM, Information Circular 9298. [accessed 10 May 2011]. Available from Internet: http://pubs.usgs.gov/usbmic/ic-9298/html/

Camm, T. W. 1994. Simplified cost models for prefeasibility mineral evaluations, Mining Engineering 46(6): 559-562.

Collier, K. 1987. Fundamentals of construction estimating and cost accounting with computer application. $2^{\text {nd }}$ Ed. New Jersey: Englewood Cliffs. 352 p.

Fan, H.; Abourizk, S.; Kim, H.; Zaïane, O. 2008. Assessing residual value of heavy construction equipment using predictive data mining model, Journal of Computing in Civil Engineering ASCE 22(3): 181-191. http://dx.doi.org/ 10.1061/(ASCE)0887-3801(2008)22:3(181)

Flury, B.; Riedwyl, H. 1988. Multivariate statistics: A practical approach. London: Chapman and Hall. 304 p. http://dx.doi.org/10.1007/978-94-009-1217-5

Gransberg, D. D.; Popescu, C. M.; Ryan, R. C. 2006. Construction equipment management for engineers, estimators and owners. Taylor \& Francis Group, UK. 552 p.

Gujarati, D. 2003. Basic econometrics. $4^{\text {th }}$ Ed. New York: McGraw-Hill. 1002 p.

Gunst, R. F. 1983. Regression analysis with multicollinear predictor variables: definition, derection and effects, Combinations in Statistics - Theory and Methods 12(19): 2217-2260.

Hassanien, A.; Moselhi, O. 2002. Automated data acquisition and planning of highway construction, in Proc. of the 19th Symposium on Automation and Robotics in Construction (ISARC 2002), 23-25 September, 2002, Gaithesburg, Maryland, 149-154.

He, F.; Ma, C. 2010. Modeling greenhouse air humidity by means of artificial neural network and principal component analysis, Computers and Electronics in Agriculture 71(Supplement 1): S19-S23.

http://dx.doi.org/10.1016/j.compag.2009.07.011

Hwang, S. 2011. Time series models for forecasting construction costs using time series indexes, Journal of Construction Engineering and Management ASCE 137(9): 656662. http://dx.doi.org/10.1061/(ASCE)CO.1943-7862. 0000350

InfoMine USA Inc., 2010. Mine and Mill Equipment Cost. [accessed 10 May 2011]. Available from Internet: http://www.costmine.com

InfoMine USA Inc., 2007. Mine and Mill Equipment Cost. [accessed 10 May 2011]. Available from Internet: http://www.costmine.com

Jennrich, R. J. 1995. An introduction to computational statistics, regression analysis. Englewood: Prentice-Hall. 364 p.

Jolliffe, I. T. 1986. Principal component analysis. New York: Springer-Verlag. 502 p.

Karan Darya Co. 2011. Sungun Sopper Complex project technical report. $56 \mathrm{p}$. 
Kim, G.-H.; An, S.-H.; Kang, K.-I. 2004. Comparison of construction cost estimating models based on regression analysis, neural networks, and case-based reasoning, Building and Environment 39(10): 1235-1242.

http://dx.doi.org/10.1016/j.buildenv.2004.02.013

Mular, A. L. 1982. Mining and mineral processing equipment costs and preliminary capital cost estimations. Canadian Institute of Mining and Metallurgy, Montreal, Special Vol. 25. 265 p.

Mular, A. L.; Poulin, R. 1998. CAPCOSTS: A handbook for estimating mining and mineral processing equipment costs and capital expenditures and aiding mineral project evaluations. Montreal: Canadian Institute of Mining and Metallurgy, Special Vol. 47. 319 p.

Nichols, H. L.; Day, D. A. 1999. Moving the earth: the workbook of excavation. $4^{\text {th }}$ Ed. McGraw-Hill. $1232 \mathrm{p}$.

Noakes, M.; Lanz, T. 1993. Cost estimation handbook for the Australian mining industry. Carlton South: Australasian Institute of Mining and Metallurgy (Aus IMM). $412 \mathrm{p}$.

O'Hara, T. A. 1980. Quick guides to the evaluation of orebodies, CIM Bulletin 73(2): 87-99.

O’Hara, T. A. 1981. Mine evaluation, Mineral Industry Costs, in J. R. Hoskins (Ed.), Northwest Mining Association, Spokane, WA, 89-99.

O'Hara, T. A.; Suboleski, S. C. 1992. Costs and cost estimation, in Mining Engineering Handbook. $2^{\text {nd }}$ Ed. SME, Littleton 1: $405-424$

Park, S.-C.; Hong, T. H.; Koo, K.-J.; Hyun, C.-T. 2010. Selection model of representative items for the subcontractors' cost index in multi-family housing projects, Journal of Civil Engineering and Management 16(2): 278-286. http://dx.doi.org/10.3846/jcem.2010.32

Petrick, A.; Dewey, R. 1987. Microcomputer cost models for mining and milling, in Mineral Resource Management by Personal Computer, Chapter 12. SME. 7 p.

Pratt, D. J. 2004. Fundamentals of construction estimating. $2^{\text {nd }}$ Ed. Thomson Delmar Learning. 413 p.

R. S. Means Company. 2005. RS Means building construction cost data $63.704 \mathrm{p}$.

Sayadi, A. R.; Lashgari, A.; Basiri, M. B. 2010a. Loading and hauling equipments maintenance cost estimation in surface mining, in International Congress on eMaintenance, 22-24 June, 2010, Lulea, Sweden, 212-217.

Sayadi, A. R.; Lashgari, A.; Oraee, K.; Yavari, M. 2010b. Hoisting equipment cost estimation in underground mines, in Haul and Hoist SME Conference, 12-17 September, 2010, Las Vegas, USA, 193-200.
Sharma, S. 1996. Applied multivariate techniques. New York: John Wiley. 512 p.

Skibniewski, M.; Armijos, A. 1990. Linear programming approach to construction equipment and labour assignments, Civil Engineering Systems 7(1) 44-50. http://dx.doi.org/10.1080/02630259008970569

Sonmez, R.; Ontepeli, B. 2009. Predesign cost estimation of urban railway projects with parametric modeling. Journal of Civil Engineering and Management 15(4): 405-409. http://dx.doi.org/10.3846/1392-3730.2009.15.405-409

Sousa, S. I .V.; Martins, F. G.; Alvim-Ferraz, M. C. M.; Pereira, M. C. 2007. Multiple linear regression and artificial neural networks based on principal components to predict ozone concentrations, Environmental Modelling \& Software 22(1): 97-103. http://dx.doi.org/10.1016/j.envsoft.2005.12.002

Stebbins, S. A. 1987. Cost estimation handbook for small placer mines. US Bureau of Mines Information Circular 9170. $94 \mathrm{p}$.

Tatari, O.; Skibniewski, M. 2006. Integrated agent-based construction equipment management: conceptual design, Journal of Civil Engineering and Management 12(3): 231236.

Thal, A. E.; Cook, J. J.; White, E. D. III 2010. Estimation of cost contingency for air force construction projects, Journal of Construction Engineering and Management ASCE 136(11): 1181-1189. http://dx.doi.org/10.1061/(ASCE)CO.1943-7862.0000227

Twort, A. C.; Rees, J. G. 2004. Civil engineering project management. $4^{\text {th }}$ Ed. Elsevier Butterworth-Heinemann. 231 p.

USBM. 1987. US Bureau of mines cost estimating system handbook. Mining and beneficiation of metallic and nonmetallic minerals expected fossil fuels in the United States and Canada. United States Bureau of Mines, Open file report 10-87, Denver, Colorado. 134 p.

Wilmot, C. G.; Mei, B. 2005. Neural network modeling of highway construction costs, Journal of Construction Engineering and Management 131(7): 765-772. http://dx.doi.org/10.1061/(ASCE)0733-9364(2005)131: $7(765)$

Zavadskas, E. K.; Vilutiené, T. 2006. A multiple criteria evaluation of multi-family apartment block's maintenance contractors: I-Model for maintenance contractor evaluation and the determination of its selection criteria, Building and Environment 41(5): 621-632.

http://dx.doi.org/10.1016/j.buildenv.2005.02.019

Ahmad Reza SAYADI. Faculty member and past head of the Department of in Mining Engineering at Tarbiat Modares University of Tehran, Iran. He has a PhD in Techniques and Economy of Mining. His research interests include mining economics, feasibility study, heavy equipment management and risk assessment. He is author or coauthor of over 50 publications on a wide range of topics in mining engineering.

Ali LASHGARI. Master of Science at the Department of Mining Engineering, Tarbiat Modares University, Tehran, Iran. He is author of more than 15 journal and conference papers in the last couple of years. His interests include construction economics and management, heavy equipment management, feasibility studies, cost estimation and equipment maintenance and operation.

Mohammad Majid FOULADGAR. Master of Science in the Dept of Strategic Management, Manager of Fateh Reaserch Group, Tehran-Iran. Author of 10 research papers. In 2007 he graduated from the Science and Engineering Faculty at Tarbiat Modares University, Tehran-Iran. His interests include decision support system, water resource, and forecasting.

Miroslaw J. SKIBNIEWSKI. A. J. Clark Chair Professor of Construction Engineering and Project Management at the University of Maryland, College Park, USA and Visiting Professor, Dept. of Management, Bialystok University of Technology, Poland. His research interests include construction equipment operations, construction information technologies and construction automation. He is past President of the International Association for Automation and Robotics in Construction, and author or coauthor of over 200 publications on a wide range of topics in construction engineering and management. 